\title{
Strengthening Technologies of Different Types of Foundations in Buildings
}

\author{
Cherney O.T ${ }^{1}$, Smirnova,Zhanna V. ${ }^{2,}$,Vaganova O.I. ${ }^{3},{ }^{2}$,azorenov V.A. ${ }^{4}$ \\ ${ }^{1}$ Minin Nizhny Novgorod State Pedagogical University (Minin University), Nizhny Novgorod, Russian Federation, \\ fiolet1975@mail.ru \\ ${ }^{2}$ Minin Nizhny Novgorod State Pedagogical University (Minin University), Nizhny Novgorod, Russian Federation, \\ z.v.smirnova@mininuniver.ru \\ ${ }^{3}$ Minin Nizhny Novgorod State Pedagogical University (Minin University), Nizhny Novgorod, Russian Federation, \\ vaganova_o@mail.ru \\ ${ }^{4}$ Minin Nizhny Novgorod State Pedagogical University (Minin University), Nizhny Novgorod, Russian Federation, \\ rvasek82@mail.ru
}

\begin{abstract}
Innovative technologies in the construction industry have taken a firm position in the construction-engineering sector. The article discusses the new technologies used for strengthening the foundations of different types. A study on the traditional method of strengthening foundations has been carried out and indicators of new technologies use are presented. Traditional options for strengthening foundations by increasing the foundation base are considered, from the point of view of geotechnics and manufacturability in relation to loose and saturated soils. The operational characteristics of new technologies during the work on strengthening the foundations are given.
\end{abstract}

Key words: building maintenance, foundation, foundation strengthening

\section{INTRODUCTION}

During long-term operation of buildings and constructions, structural deformations occur. When constructing buildings on loose soils, the main causes of deformations are uneven precipitation, which causes the destruction of the foundations, walls, columns, and floors themselves. In addition, the destruction of foundations can occur as a result of an emergency.

The choice of technology for strengthening foundations depends on the building condition, as well as the risk category of the proposed conservation, restoration or reconstruction work. Reconstruction can be associated with increased loads on existing foundations due to additional structures, replacement of wooden floors with concrete ones, changes in technology, etc. The factors related to the structural features of the building, the state of the soil at the base and the equipment are fundamental when choosing the strengthening technology. The equipment can be used to strengthen foundations and bases technologically, quickly, safely, with minimal use of manual operations[1].
Modern calculation methods make it possible to make highly competitive technology options to strengthen the foundation based on geological and engineering data. Traditional technologies cannot be abandoned without a proper calculation justification. In combination with new, modern technologies, they often have a positive effect.

In complex reconstruction cases, as a rule, several processing methods are used. Thus, for instance, fragmentary traditional foundation re-laying can be performed with injection technologies.

In all cases, the proposed technology should enable reliable long-term operation of the building, corresponding to the geological and engineering prediction. Economic, environmental, and work safety issues must be taken into account. The environmental aspect concerns mainly numerous chemical methods of artificial improvement of soil properties. The consequences of intervention into the natural hydrogeological environment are unpredictable.

\section{RESEARCH}

During the researchof new technologies to strengthen the foundation, we examine and analyze traditional and new technologies of strengthening bases and foundations, preassessing the reasons for such strengthening. According to the generalized classification of B. I. Dalmatov,this happens primarily due to:

-increased load on foundations;

-foundationmasonryfailure or reduction of its waterproofing properties;

-deterioration of stability conditions of foundations or soils at their base;

- increase of the soil deformation properties;

-continuous development of unacceptable displacements of the structures [2].

Exploring the traditional strengthening method, the main mistakes of the process during the construction of old buildings were highlighted, in which strengthening technologiesof bases and foundations mainly came down to increase the area of bearing of the existing foundations and, consequently, decreasing the pressure on the foundation soil (Figure 1). 


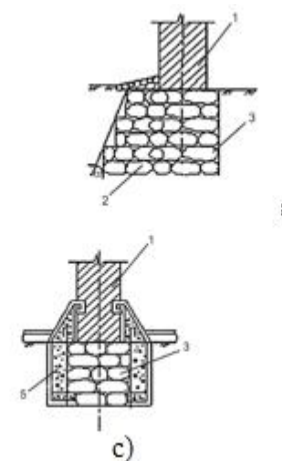

a)
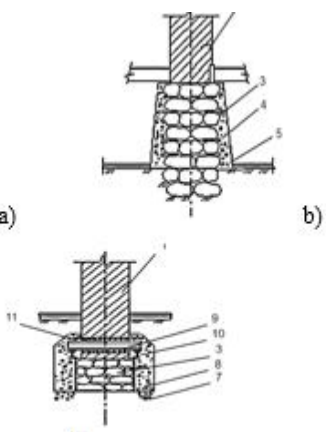

d)

Figure 1: Traditional foundation strengthening technologies:

a-leveling bond; b, d- concrete column; C- concrete collar; 1-wall; 2-new masonry bonded with the old one; 3 - old masonry; 4-metal pins; 5-concrete column; 6- concrete collar column; 7- gravel layer; 8-concrete bankets; 9 operation beam; 10-distribution beam; 11- cast concrete caulking

The increase in the foundation base achieved mainly by creating reinforced concrete columns or bankets (single and double-sided). In the past,to widen the foundations, levelling with bonds to the existing masonry was done(Figure 1 a). The bonds were supported at various levels. Thus, the excavation of old foundations in Vyborg, Novgorod, Pskov showed that the bonds remained in the bulk soil and did not actually affect the conditions for further operation of buildings. They were in operation only with large deformations after the appropriate compaction of the soil at the base of the widened part[3].

Let us consider the traditional options for strengthening foundations associated with widening of the foundation base, from the standpoint of geotechnical engineering and manufacturability in relation to loosewater-deposited soils. Widening of the foundation base without pre-crimping is ineffective. As it was mentioned above, they only come into operation when the load increases, when there is additional precipitation. This is clearly seen in figure 2 .

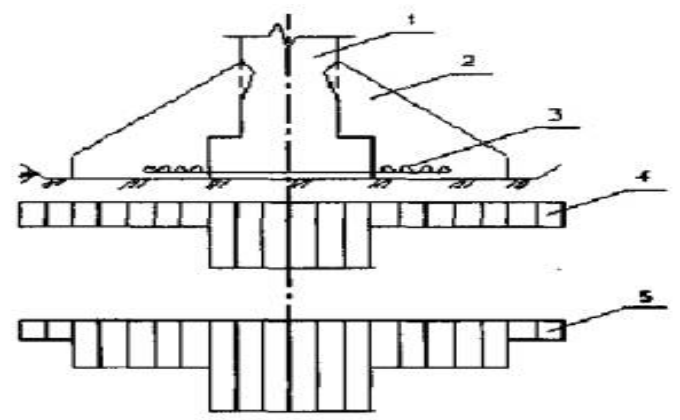

Figure 2:Diagram of widening of the foundation base (with pressure diagram in the foundation base) by B. I. Dalmatov:

1-existing foundation; 2-wideningstructure; 3 reinforcement; 4-pressure diagram before widening; 5pressure diagram after widening and loading the foundation

Strengthening of foundation bases, as a rule, is made in the case when the soil is overloaded, i.e. under the edges of the foundations there are developed yielding areas. When

opening such foundations (even local ones) to thefoundation base, the soil may be forced into a trench or a pit (Figure3)

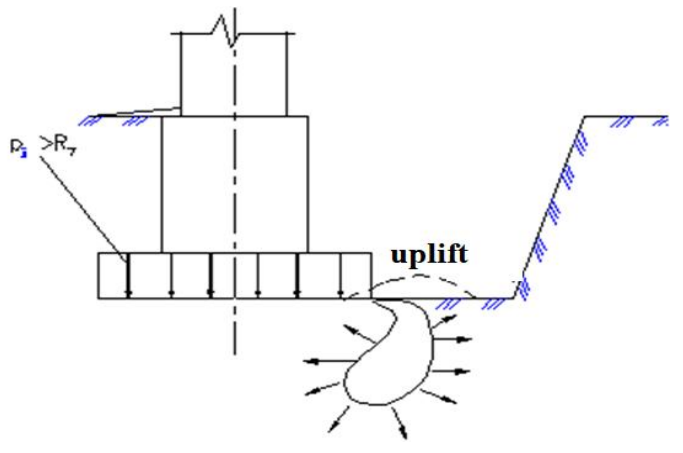

Figure 3: Possible foundation uplift when digging a trench to the foundation base of the existing one (with the use of traditional technologies).

As observations have shown, a significant part of the load will be transmitted through the foundation base of the old one. This can be considered acceptable, since widening improve overall load transfer conditions, excluding the uplift from under the foundation base. However, the uplift may occur during the process. A possible upliftshould be predicted by calculation.

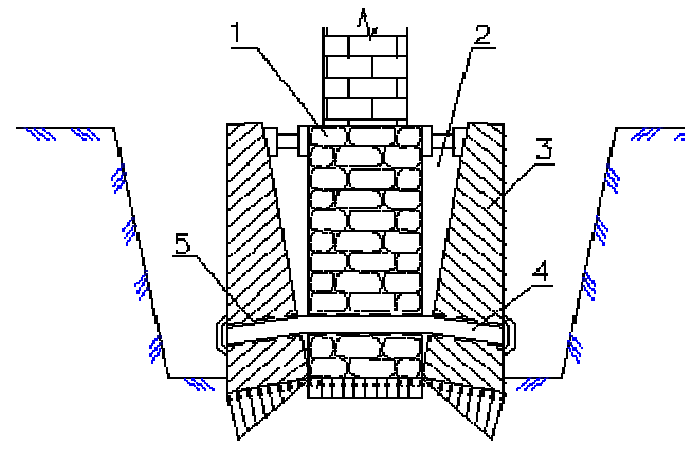

Figure 4: Foundation strengthening with extra blocks that compress the foundation soils when they turn (according to N. I. Strabakhin):

1-existing foundation; 2-a gap that opens when the blocks are rotated; 3-reinforced concrete block; 4-anchor fastening; 5-holes for anchors.

Thus, even using the simplest traditional strengthening method, the problems of technology, geology and engineering are closely intertwined. All the considered strengthening methods are complex and expensive, and most importantly, they are performed mainly manually [4]. The research of such technologies has shown that more technological processes and materials are needed in the process of foundation strengthening.

\section{RESULTS AND DISCUSSION}

In world practice, there is a great number of various chemicals that can fix the base soil for a long period. The advantages of chemical methods include: a high degree of mechanization of all operations; the ability to strengthen the soil to the parameters set by the project in their natural 
conditions; relatively low labour intensity, a sharp reduction in manual unskilled labour for digging trenches, as well as a relatively low cost of raw materials (the possibility of using production waste) [5].

A relatively new technology, developed by V. E. Sokolovich in the early 70's, was called gas silicatization. The essence of the method is that carbon dioxide is initially introduced into the stabilized soil (under the pressure of up to $0.2 \mathrm{MPa}$ ) to activate the surface of mineral particles, and then a solution of liquid glass with a density of $1.19-1.30 \mathrm{~g} / \mathrm{cm} 3$ (depending on the permeability of the soil). Gas silicatization, unfortunately, does not extend the use of the method; its use is limited to sand differences with a filtration coefficient of up to 0.5 $\mathrm{m} /$ day.

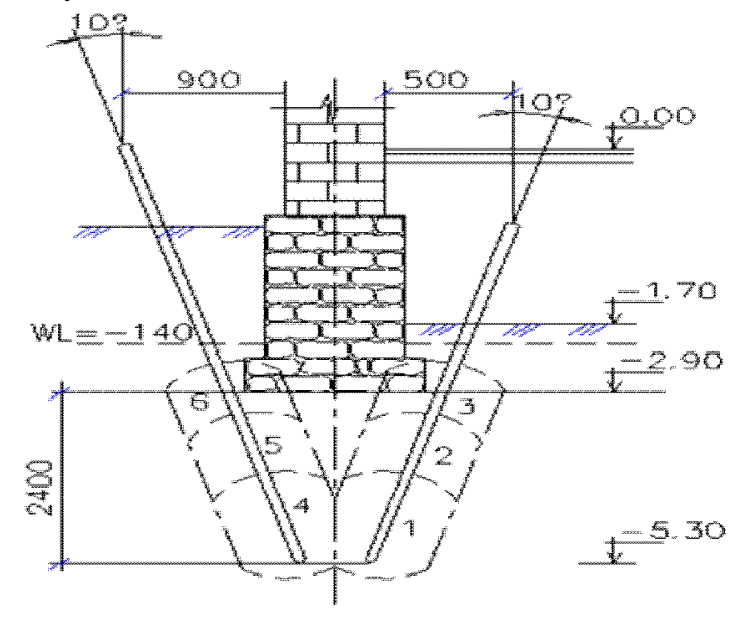

Figure 5: Electrochemical fixing of loose soils at the base of foundations:

1-6-capture numbers

The traditional technologies mentioned above, related to the foundation base widening, can be transformed in the following way at the present stage. At the basement level, a reinforced concrete slab 2 (Figure 6) is installed, fixed in the foundation body. To ensure that the plate is reliably included in the work, one can inject cement solution for pressing the upper layers of the soil under it. This strengthening method was successfully implemented by the authors on a residential building on Bolsheokhtinsky Ave., 31, loose soils at the base of which did not provide the perception of loads from existing foundations. Bringing the plate prevented the development of uneven precipitation and saved the building [6].

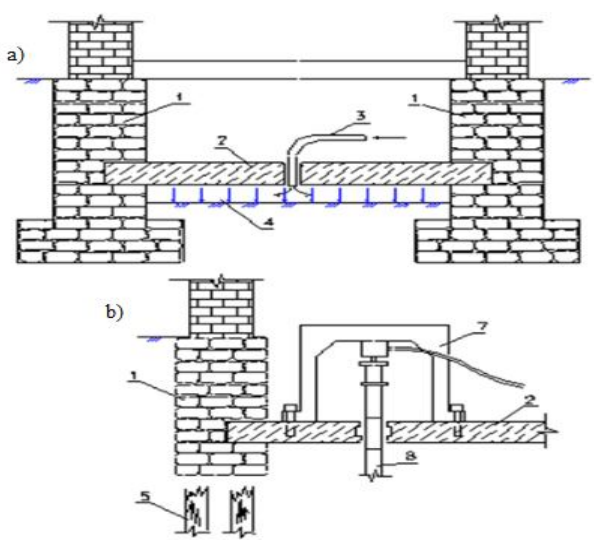

Figure 6:Increase in bearing area using a solid-cast concrete slab:

a - with the pressure testing of soil; $b$ - with multi-pile pressing; 1 - existing foundation; 2 - concrete slab; 3 intrusion pipe for expansive cement; 4 cement mortar between the plate and ground; 5 - rotten wooden piles; 6 adjustable jack; 7 - supporting rocker arm; 8 -jack pile

Currently, the reinforcement design with legged pilesand a reinforced concrete slab device has been developed and implemented (Figure 7).

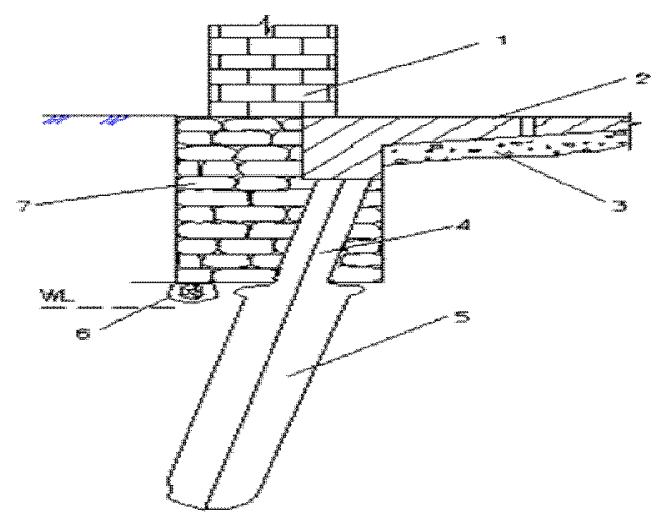

Figure 7: Construction of a short-legged pile and a reinforced concrete slab:

1-wall; 2-reinforced concrete slab; 3 - grout with cement; 4-pile in the conductor pipe; 5-widened part of the pile; 6grating beam; 7-rubble stone foundation

In this case, the reinforced concrete slab can be included in the operation with the foundation and foundation soil. Freezing does not affect structures that are reinforced inside the building.

To exclude undesirable dynamic effects on old buildings and loose soils, pile installation by pressing can be made. Taking into consideration the tightness of existing premises, multi-section piles are often used.

Technological features of multi-section pilesin the form of stabilizers are shown in Figure 8 a. 


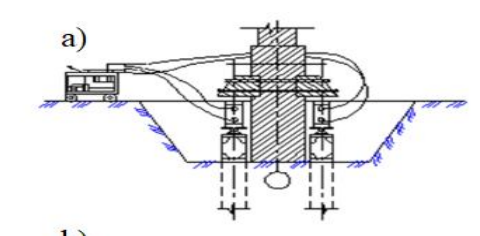

b)

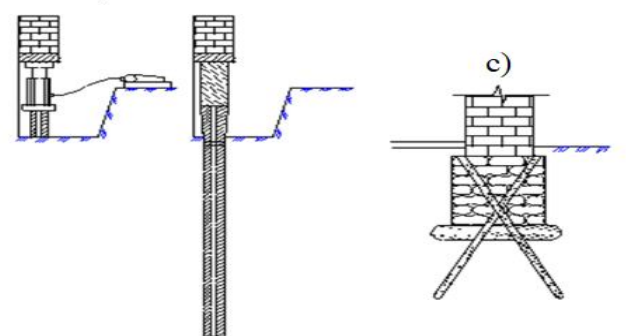

Figure 8: Foundation strengthening using piles:

a-multi-sectionpressing piles with a double-sided beamstop; b- piles pressing under the wall or the foundation base; c-bored piles with a contact layer.

When using pressing piles, reliable stops are required. The load-bearing capacity of the pile can be adjusted during the pressing of multi-section elements. The latter can be made of reinforced concrete in the form of sections with special joints that allow quick connection.

The main advantages of root piles:

Manual earthworks are completely excluded. Drilling wells is carried out directly through the foundation, without affecting communications that pass near buildings and in basements [7].

Using small-sized equipment, one can work from the basement height of $2.0-2.5 \mathrm{~m}$. If necessary, work can be carried out from the first floor of the building.

The appearance of the structure does not change at all, which is important when working on architectural monuments.

It is possible to work at existing enterprises without stopping the production process.

Manual labour costs for all technological operations are minimal; the method is economical, with low material consumption.

The environmental purity of the method is obvious in comparison with chemical methods of fixing, which is important in conditions of strict environmental control [8]. An important stage in the formation of a bored pile body, arranged in loose soils under a clay solution, is crimping. The subsequent friction resistance along the side surface of the pile and, accordingly, its load-bearing capacity depend on the pressure and crimping time. There is a partial cementation of the soil at the contact between pile and soil. In loose soils, when pressing at a pressure of 0.2-0.4 $\mathrm{MPa}$, the soil around the pile is compacted, the crosssection of the pile increases, and the existing cavities are filled with a solution.

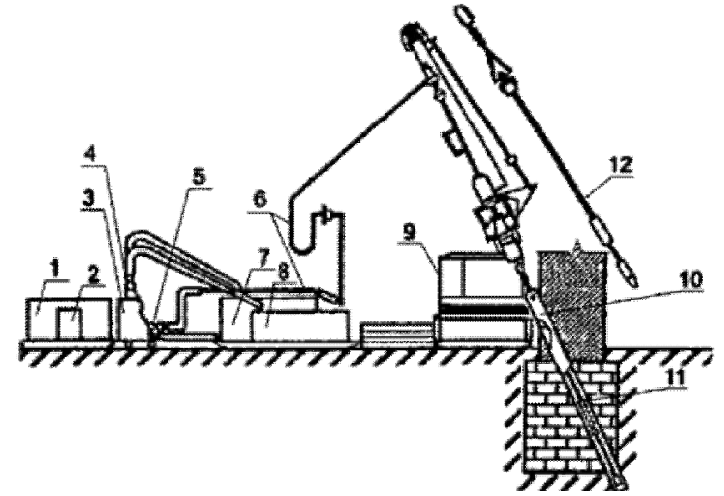

Figure 9: Drill and inject complex in the process of making a pile:

1-container for cement mortar; 2-mud mixer; 3- gaugingtank; 4-solution pump; 5-washing pump; 6-pressure pipeline; 7-container for clay solution; 8-sludge collector; 9-drilling machine; 10- conductor pipe; 11-drilling tool; 12-drill pipe

The main advantages of cement grout jetting in loose soils are the ability to work in any unfavorable ground and in confined conditions, environmental cleanliness of all process operations.

\section{CONCLUSION}

Thus, in each particular case, there are multi-dimensional geological and engineering problems, the solution of which requires comprehensive information about the soil, changes in their properties during long-term operation, in the process of conducting work on the construction of new foundations or underground structures near them. Issues concerning strengthening of bases and foundations should be solved in a complex with strengthening of aboveground structures. The example of this is the strengthening of an architectural monument in Rome. Here, along with strengthening the foundations with root-piles, the main aboveground structures, including the brickwork of the walls, were reinforced. It should be taken into account that anchoring brick walls with metal rods may be ineffective and dangerous due to metal corrosion, which results in an increase in the volume of corroding metal and, consequently, an integrity damage of the reinforced structures.However, the main source of the most significant deformations remains incorrect understanding of soil properties or underestimation of possible consequences associated with their structuringduring the reconstruction work.

\section{REFERENCES}

1. Tetior, A. N. Bases and foundations / Tetior A. N.. Moscow: Academia, 2012. - 446 p.

2. Ukhov, S. B. Terramechanics, bases and foundations / Ukhov S. B., Semenov V. V., Vasilevsky V. V., and others. - Moscow: Higher school; 2nd Edition,edited, 2002. - 566 p.

3. Tsytovich, N. A. Bases and foundations / Tsytovich N. A. -M.: HER Media, 2012. - 418 p. 
4. Smirnova, Z.V., Vaganova, O.I., Cherney, O.T., Romanovskaya, E.V., Andryashina, N.S., Toshin, D.S. The organization of emergency and dispatching servicing of an apartment house// International Journal of Innovative Technology and Exploring Engineering 8(9), 2019. p. $1477-1480$

https://doi.org/10.35940/ijitee.I8194.078919

5. Smirnova, Z.V., Mukhina, M.V., Katkova, O.V., Gruzdeva, M.L., Chernei, O.T. Network Interaction as a Factor of Professional Qualities' Development of Service Workers//Lecture Notes in Networks and Systems, 87, pp. 698-704. International Journal of Innovative Technology https://doi.org/10.1007/978-3-030-29586-8_81

6. Sokolovsky A.A., Zemtsov A.I., Kovalev D.I., ShishkovE.M., Kazantsev A.A. Hybrid Fiber Optic
Temperature Sensor Powered by Optical Radiation International Journal of Emerging Trends in Engineering Research Volume 7, No. 12 December 2019

https://doi.org/10.30534/ijeter/2019/217122019

7. Y. Pratapa Reddy, Dr. K. L Narayana, Dr. M. Kedar Mallik. Electro-chemical behaviour of different metals in Sodium Chloride solution// International Journal of Emerging Trends in Engineering Research Volume 7, No. 11 November 2019.

https://doi.org/10.30534/ijeter/2019/507112019

8. Smirnova Zh.V, Cherney O.T. Laser alloying technology when changing the processing speed// International Journal of Emerging Trends in Engineering Research. Volume 8. No. 4, April 2020.

https://doi.org/10.30534/ijeter/2020/40842020 